\title{
Respiration during sleep in normal man
}

\author{
NEIL J DOUGLAS, DAVID P WHITE, CHERYL K PICKETT, JOHN V WEIL, CLIFFORD W \\ ZWILLICH
}

From the Cardiovascular Pulmonary Research Laboratory, University of Colorado Health Sciences Center, Denver, Colorado, USA

ABSTRACT Respiratory volumes and timing have been measured in 19 healthy adults during wakefulness $\stackrel{x}{\omega}$ and sleep. Minute ventilation was significantly less $(\mathrm{p}<0.05)$ in all stages of sleep than when the subject was awake (7.66 $\pm 0 \cdot 34(\mathrm{SEM}) \mathrm{l} / \mathrm{min})$, the level in rapid-eye-movement (REM) sleep $(6.46 \pm 0.291 / \mathrm{min}) \overrightarrow{\text { o }}$ being significantly lower than in non-REM sleep $(7 \cdot 18 \pm 0.391 / \mathrm{min})$. The breathing pattern during all $\ddagger$ stages of sleep was significantly more rapid and shallow than during wakefulness, tidal volume in REM 은 sleep being reduced to $73 \%$ of the level during wakefulness. Mean inspiratory flow rate (VT/Ti), an index of $\rightarrow$ inspiratory drive, was significantly lower in REM sleep than during wakefulness or non-REM sleep. Thus $z$ ventilation falls during sleep, the greatest reduction occurring during REM sleep, when there is a parallel $\overbrace{\mathbb{S}}$ reduction in inspiratory drive. Similar changes in ventilation may contribute to the REM-associated $\frac{\Xi}{\square}$ hypoxaemia observed in normal subjects and in patients with chronic obstructive pulmonary disease.

The identification of patients with sleep-related disorders of breathing and oxygenation ${ }^{12}$ has heightened interest in breathing during sleep in both patients ${ }^{3-5}$ and normal subjects. ${ }^{6}$ Although some of these events have a clear relationship to EEG sleep stage, appreciable oxygen desaturation occurring almost exclusively in rapid-eyemovement (REM) sleep in chronic obstructive pulmonary disease, ${ }^{245}$ there have been few studies ${ }^{78}$ of ventilation in normal adult man during sleep with electroencephalographic documentation of sleep stage. In addition, minute ventilation has never been measured during REM sleep in adult man.

To try to understand the pathophysiology of these sleep-related breathing abnormalities, we have compared expired volumes and respiratory timing in normal adults during wakefulness with those in the different electroencephalographic stages of sleep.

\section{Methods}

Nineteen healthy adults were studied, eight men (mean age $32.4 \pm 1.8$ (SEM) years) and 11 women (26.5 \pm 1.3 years). None of the subjects was obese or had any sleep complaints, and none was taking oral contraceptives or any other medication. All subjects had resided for at least six months in Denver (altitude $1600 \mathrm{~m}$ ), where the studies were performed. Each subject was a regular nocturnal sleeper and all studies were performed between $10 \mathrm{pm}$ and 7 am without prior sleep deprivation. Every subject gave informed consent to the study, which had the approval of the institute's human subject research committee.

Address for reprint requests: Dr Neil J Douglas, Department of Medicine, Royal Infirmary, Edinburgh EH3 9YW.

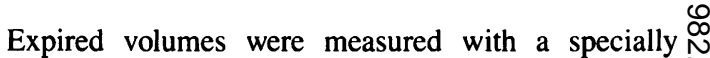
constructed fibreglass mask ${ }^{9}$ with built-in inspiratory and expiratory valves, the system having a dead space of $70-85 \mathrm{ml}$ (the amount depending on the subject's facial structure). A perforated polyethylene catheter around the circumference of the mask's face cushion was continuous- $\frac{\circ}{\Phi}$ ly sampled by an infrared analyser (Beckman LB2) set to maximal gain. This system is capable of detecting an $\overrightarrow{0}$ expired leak of $1.2 \%$ when tested in closed circuit. ${ }^{9} \mathrm{We}$ report the results of those studies in which there was no detectable leak throughout.

Expired flow was measured with a hot wire anemometer (Therm-Systems Inc) calibrated against rotameters traceable to the United States National Bureau of $\underset{\sigma}{\times}$ Standards. End-tidal oxygen tension $\left(\mathrm{PO}_{2}\right)$ was measured 3 by a fuelcell ${ }^{10}$ and end-tidal carbon dioxide tension $\left(\mathrm{PCO}_{2}\right)$ by another infrared analyser (either Beckman LB2 or $\frac{\text { ㅇ }}{3}$ Goddart Capnograph). End-tidal analysers were calibrated before each study against gas mixtures previously analysed by the Scholander technique, " and the calibra- $\frac{D}{O}$ tions (which were checked at least every 90 minutes during each night) were always found to be accurate to $\mathcal{N}$ within $1.5 \%$. End-tidal concentrations and flows were $\mathrm{N}$ analysed breath by breath on a Nova 1200 computer. 공

Continuous recordings were made on a polygraph ${ }^{\omega}$ recorder (Grass Model 78D) of the electoencephalogram $₹$ (by silver disc electrodes in the central and occipital ${ }^{\circ}$ regions), electro-oculogram (by one electrode lateral to $ळ$ each outer canthus and one near the nasion), and ${ }^{+}$ electromyogram (by two submental electrodes). Sleep $\frac{0}{0}$ stage was determined by standard criteria ${ }^{12}$ and scored $\frac{}{\Phi}$ every 15 seconds. As stages 3 and 4 tended to intermingle $\frac{\stackrel{\rho}{\mathbb{P}}}{\mathbb{P}}$ and there was no difference between the breathing $\varrho$ 
volumes or patterns between these stages their results have been merged as "staged $3 / 4$ ".

With the subjects lying in bed we recorded baseline ventilation both before and after sleep during EEGconfirmed wakefulness, and as there was no statistical difference between the values obtained before and after sleep these results have been combined to produce the "awake" value. This value was then compared with the mean result during each stage of sleep. Measurements during sleep are quoted only if $(a)$ the subject had been in a stable sleep stage for at least two minutes; $(b)$ there was no sleep stage change, however brief, during the study; and $(c)$ there was no detectable leak throughout. These studies were performed in conjunction with measurements of hypoxic ${ }^{9}$ and hypercapnic ventilatory response during sleep, but all data quoted were obtained when the subjects had been breathing room air for at least 10 minutes.

One subject was studied on three nights, nine on two nights, and nine on one night. No significant difference was found in either respired volumes, breathing pattern, or EEG sleep pattern between the first and subsequent night's sleep in those studied on more than one night. Results given represent $5.46 \pm 0.46$ minutes per subject per sleep stage, with no significant difference bet ween the durations in wakefulness or the various stages of sleep.

The significance of changes observed between sleep stages was assessed by two-way analysis of variance and the Student-Newman-Keuls multiple-comparison test. ${ }^{13}$ Differences between the sexes were assessed by Student's unpaired two-tail $t$ test. Results are given as means \pm standard errors.

\section{Results}

Minute ventilation was significantly lower in all stages of sleep than in wakefulness ( $<<0.05$, fig 1$)$, falling from $7.66 \pm 0.34 \mathrm{l} / \mathrm{min}$ during wakefulness to $7.24 \pm 0.39$ $1 / \mathrm{min}$ in stage 2 and $7 \cdot 09 \pm 0 \cdot 39 \mathrm{l} / \mathrm{min}$ in stage $3 / 4$. There was no significant difference in the levels of ventilation in non-REM sleep (stages 2 and 3/4) but there was a further significant $(\mathrm{p}<0.05)$ fall in REM sleep $(6.46 \pm 0.29$ $1 / \mathrm{min}$ ), when minute ventilation was reduced to $84 \%$ of the level during wakefulness. This reduction in ventilation was due to a breathing pattern which, although slightly more rapid during sleep $(p<0.05)$, was considerably shallower in all stages of sleep than during wakefulness ( $p$ $<0.05$ ), with a significantly lower tidal volume in REM than in stage 2 sleep (fig 1). Mean inspiratory flow rate $(\mathrm{VT} / \mathrm{Ti})$, an index of inspiratory ventilatory drive, was significantly lower in REM sleep than in either wakefulness or non-REM sleep $(p<0.05)$ (fig 2$)$. There was no significant difference in the respiratory duty cycle, Ti/TOT, between any stages (fig 2). The subjects were significantly more hypoxic and hypercapnic in all stages of sleep than during wakefulness (fig 3), with greater changes during REM sleep than in stage 2 ( $p<0.05$ ). There were no significant differences between the sexes either in ventilation (corrected for body surface area) or in end-tidal concentrations during any stage of sleep.

Breathing patterns tended to be regular in non-REM sleep (fig 4), with two exceptions. Firstly, in all subjects tidal volume tended to be variable in the first few minutes after sleep onset and after any arousal. Secondly, in four of the men such irregular breathing continued throughout the initial one to four hours of non-REM sleep (fig 4) but became regular in all cases thereafter. In all subjects the breathing pattern in REM sleep was irregular throughout the night (fig 4).
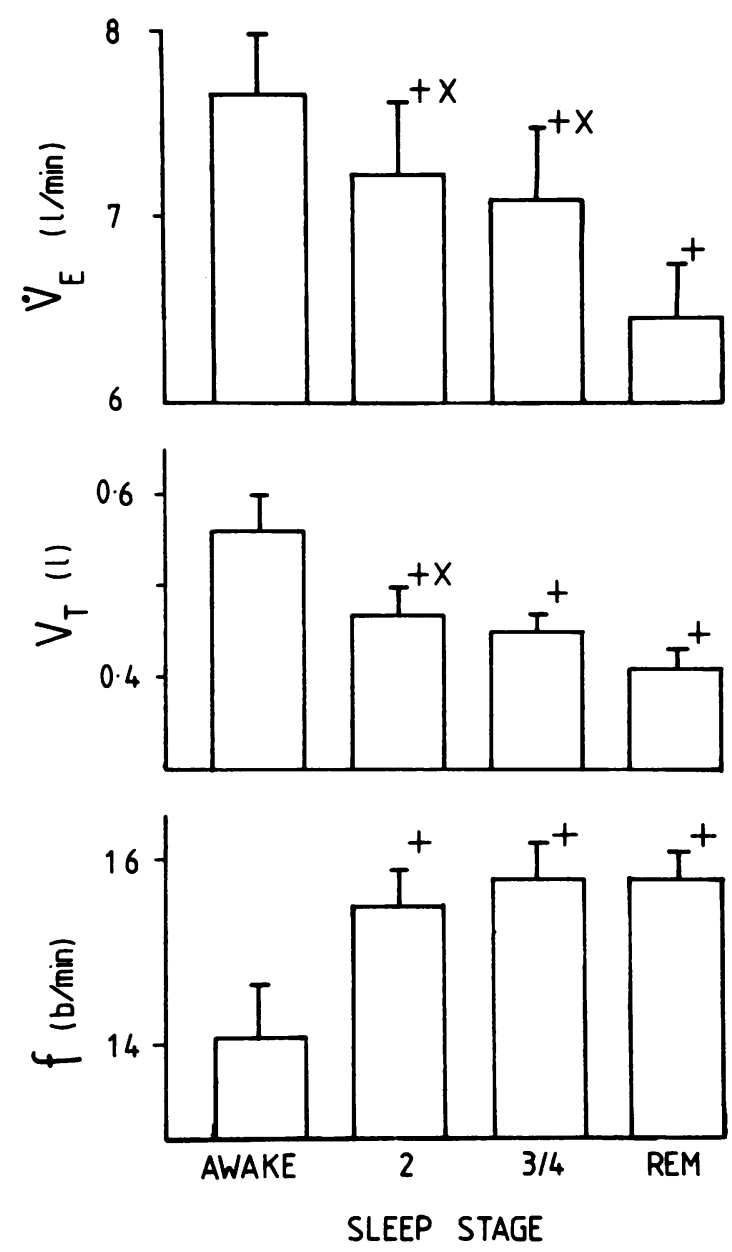

Fig 1 Minute ventilation $\left(\dot{V}_{E}\right)$, tidal volume $(V T)$, and breathing frequency $(f)$ during wakefulness and different sleep stages. $\dot{V} E$ is reduced in non-REM sleep, with a further reduction in REM sleep owing to shallower breathing (mean $\pm S E$ for 19 subjects).

$+: p<0.05 \mathrm{v}$ awake; $\times: p<0.05 \mathrm{v}$ REM sleep. 

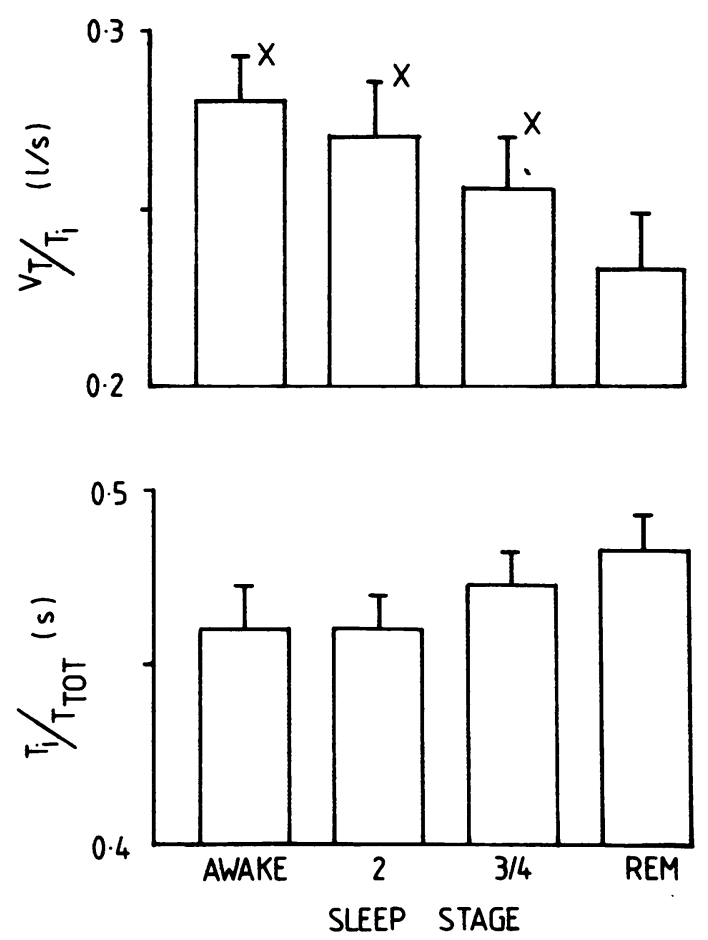

Fig 2 Inspiratory drive (VI/Ti) and respiratory duty cycle ratio (Ti/Tror) during wakefulness and different sleep stages. Vi/Ti is reduced in $R E M$ sleep (mean $\pm S E$ in 19 subjects). $\times: p<0.05 \mathrm{v}$ REM sleep.

\section{Discussion}

We have shown that normal people breathe more rapidly and shallowly in all stages of sleep than during wakefulness, the lowest mean tidal volume occurring in REM sleep, when the depth of breathing was highly variable. These changes resulted in lower expired volumes in non-REM sleep than during wakefulness, with a further appreciable reduction in ventilation during REM sleep, which was associated with a parallel reduction in inspiratory drive $\left(\mathrm{VT}_{\mathrm{T}} / \mathrm{Ti}\right)$.

Our results for non-REM sleep agree with those of Bülow, ${ }^{7}$ who found a similar pattern of reduced ventilation with rapid shallow breathing, and with those of earlier workers, ${ }^{14-16}$ who while not recording an EEG observed decreased ventilation during what was almost certainly non-REM sleep. Duron ${ }^{8}$ found no difference between ventilation during wakefulness and non-REM sleep, but he studied only four subjects. Our findings of rapid shallow breathing in REM sleep with a variable tidal volume agree with those of Bülow ${ }^{7}$ and Duron, ${ }^{8}$ but neither measured overall ventilation in REM sleep. Bülow, however, noted that "ventilation in REM varied around the same mean" as in drowsiness, when ventila-
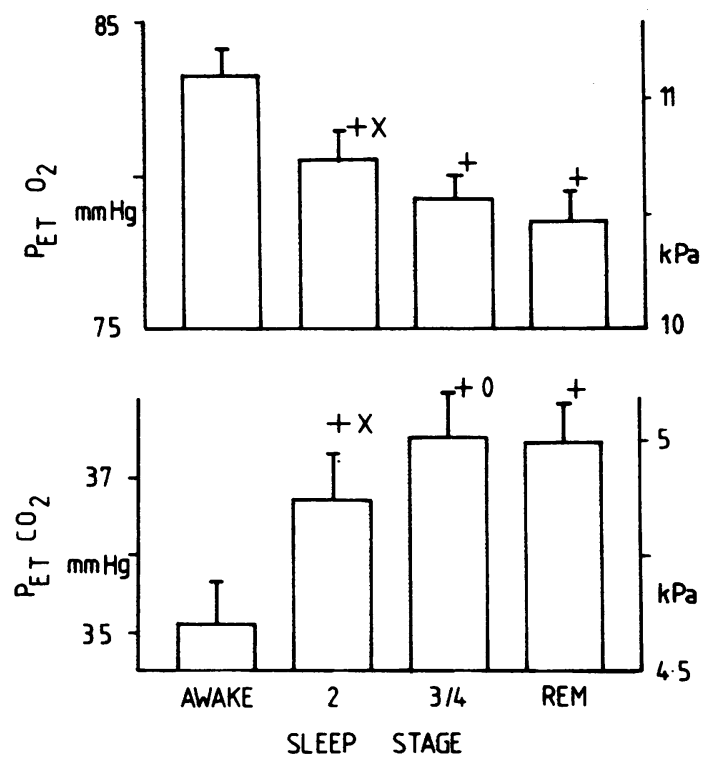

Fig 3 End-tidal $\mathrm{PO}_{2}\left(\mathrm{P}_{\mathrm{KT}} \mathrm{O}_{2}\right)$ and $\mathrm{PCO}_{2}\left(\mathrm{P}_{\mathrm{HT}} \mathrm{CO}_{2}\right)$ during wakefulness and different sleep stages. Oxygenation was lover and carbon dioxide tension higher in stage 2 sleep than during wakefulness, with further changes in stage $3 / 4$ and REM sleep. Mean $\pm S E$ in 19 subjects. $+: p<0.05$ vawake: $\times: p<0.05 \mathrm{v}$ REM sleep; $0: p<0.05$ v stage 2 sleep.
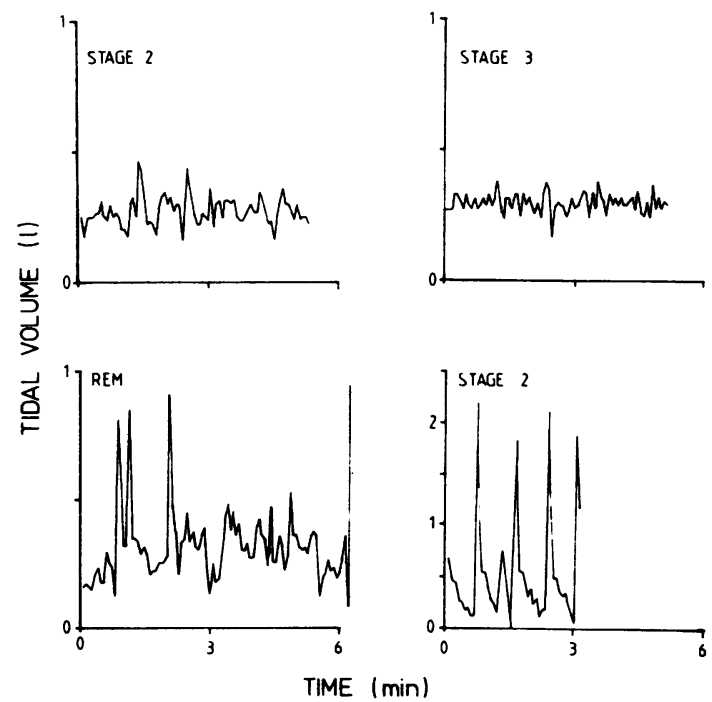

Fig 4 Examples of the usual patterns of breathing in stage 2 (top left), stage 3, and REM sleep, showing the variable depth of breathing in REM sleep. In four men ventilation tended to be highly variable in stage 2 during the first half of the night (botiom right). 
tion was $13 \%$ lower than during wakefulness but was higher than in stage 2 sleep. He does not state the number of subjects on whom this observation was made.

In infants most studies ${ }^{17-19}$ have shown that breathing is shallower in REM than non-REM sleep as in adults but that, unlike in adults, the effect of this on overall ventilation is more than offset by a considerable increase in frequency, so that minute ventilation is higher in REM sleep. Other studies in infants have shown no change in tidal volume $e^{20} 21$ or frequency ${ }^{20}$ between REM and non-REM sleep. Our results differ from these because of maturity of ventilatory control, the respiratory pattern in infants being very different from that in adults with breathing frequencies of around 45/min in non-REM and $60 /$ min in REM sleep. Tabachnik and colleagues ${ }^{22}$ recently found that in adolescents (mean age 15 years) ventilation is $8 \%$ lower in non-REM sleep and 5\% lower in REM sleep than during wakefulness. The absence of a reduction in ventilation between non-REM and REM sleep in these subjects might reflect either their younger age or the use of an inductive plethysmograph, as this apparatus has not been quantitatively validated for the accurate measurement of ventilation during sleep, when changes may occur not only in the relative contributions and phase relationships of chest and abdomen but also in body posture. Animals differ from adult man in that breathing becomes slower and deeper in non-REM sleep and more rapid and shallow in REM. ${ }^{23-25}$ Overall, ventilation is lower in non-REM sleep than during wakefulness $^{24} 25$ and in REM sleep is lower still in cats ${ }^{24}$ but increased in $\operatorname{dogs}^{25}$ owing to an appreciable increase in frequency. These results are probably explained by species differences between dog, cat, and man.

The reduction in minute ventilation during sleep resulted in hypoxia and hypercapnia, as has previously been shown in normal subjects, ${ }^{7}{ }^{126}$ although these earlier observations were made either without EEG monitoring ${ }^{1526}$ or without differentiation between REM and non-REM sleep. Although in this study ventilation was lowest in REM sleep, no significant difference was found between end-tidal levels in stage 3/4 and REM sleep. This is probably because end-tidal levels during REM sleep are variable owing to the variable tidal volume, and are often spurious when very small breaths are taken. Thus the choice of a single end-tidal level for each REM study is an error-riddled oversimplification.

An alternative method of assessing the physiological significance of the decrease in minute ventilation would have been to record alveolar ventilation. Although this was not measured in our study, if we calculate physiological dead space, ${ }^{27}$ which is known not to vary between sleep stages, ${ }^{7}$ and assume a mask dead space of $80 \mathrm{ml}$, alveolar ventilation is found to be lower in all stages of sleep than during wakefulness - the decreases being $19 \%$ in stage $2,26 \%$ in stage $3 / 4$, and $39 \%$ in REM sleep. The decrease in ventilation is accompanied by a significant reduction in mean inspiratory flow rate $\left(\mathrm{V}_{\mathrm{T}} / \mathrm{Ti}\right)^{28}$ in $\mathrm{REM}$ sleep (fig 2), similar to a trend noticed by Remmers et al in cats. ${ }^{23}$ In the absence of any evidence of increased bronchoconstriction between non-REM and REM sleep in adults, ${ }^{29}$ the hypoventilation in REM sleep is likely to be due to decreased ventilatory drive rather than to mechanical factors.

The increased respiratory frequency during sleep was due to parallel significant decreases in inspiratory (Ti) and expiratory (Te) times during sleep, these changes being similar in all sleep stages. Thus the respiratory duty cycle ratio (Ti/Tтот) ${ }^{28}$ was unchanged by sleep. Such parallel reductions in inspiratory and expiratory times also occur during carbon dioxide rebreathing ${ }^{30}$ and may indicate changes in the inspiratory "off-switch" sensitivity" occurring in the brain stem during sleep.

The breathing pattern was predominantly regular in non-REM sleep (fig 4) except for a few minutes after arousal, when irregularity occurred in all subjects and for much longer periods (one to four hours) during the first half of the night in four of the men (fig 4, bottom right). In these subjects the breathing pattern was grossly irregular, the irregularity being associated with snoring in one subject. As the sleep apnoea syndrome is also a condition of men with grossly irregular breathing, particularly in stage 2 sleep, and is often associated with snoring, possibly these four subjects have a defect of respiratory function, which if combined with obesity, with or without other factors, might lead to development of the sleep apnoea syndrome. Irregular breathing in REM sleep on the other hand occurred throughout all REM periods in all the men and women.

Despite previous suggestions that ventilation in sleep might be different in men and women, ${ }^{6}$ we could find no difference in the mean levels of ventilation or oxygenation between the sexes in any sleep stage. This disparity is perhaps due to the inclusion of obese men as normal subjects in the previous study, ${ }^{6}$ these subjects contributing a large proportion of the "sleep-disordered breathing" reported. Nevertheless, episodes of appreciable irregular breathing such as we observed in four of the men might account for a sex difference in "sleep-disordered breathing," even though the mean levels of ventilation were the same in both sexes.

This study shows that hypoventilation and resulting hypoxia occur normally during sleep, particularly in REM sleep. Thus the hypoxia and associated hypoventilation during REM sleep previously reported in patients with chronic bronchitis and emphysema ${ }^{24532}$ and various other disease states ${ }^{33} 34$ are merely normal phenomena. These episodes are, however, almost certainly of considerable clinical importance, contributing to the development of pulmonary hypertension and secondary polycythaemia in such patients. ${ }^{4}$ 
This study was supported by National Institutes of Health program project grant HL 14985. Dr Douglas was a Medical Research Council (UK) travelling fellow. Dr Zwillich is the recipient of National Institutes of Health (USA) research career development award HL 00225.

\section{References}

${ }^{1}$ Guilleminault C, Tilkian A, Dement WC. The sleep apnea syndromes. Annu Rev Med 1976;27:465-84.

${ }^{2}$ Koo KW, Sax DS, Snider GL. Arterial blood gases and $\mathrm{pH}$ during sleep in chronic obstructive pulmonary disease. Am J Med 1975;58:663-70.

${ }^{3}$ Flick MR, Block AJ. Continuous in-vivo monitoring of arterial oxygenation in chronic obstructive lung disease. Ann Intern Med 1977;86:725-30.

${ }^{4}$ Douglas NJ, Calverley PMA, Leggett RJE, Brash HM, Flenley DC, Brezinova V. Transient hypoxaemia during sleep in chronic bronchitis and emphysema. Lancet 1979;i:1-4.

${ }^{5}$ Fleetham JA, Mezon B, West P, Bradley CA, Anthonisen NR, Kryger MH. Chemical control of ventilation and sleep arterial oxygen desaturation in patients with COPD. Am Rev Respir Dis 1980;122:583-9.

${ }^{6}$ Block AJ, Boysen PG, Wynne JW, Hunt LA. Sleep apnea, hypopnea and oxygen desaturation in normal subjects. $N$ Engl J Med 1979;300:513-7.

${ }^{7}$ Bülow K. Respiration and wakefulness in man. Acta Physiol Scand 1963;59:suppl 209.

${ }^{8}$ Duron B. Respiratory function during physiological sleep. Bull Physiopath Respir 1972;8:1031-57.

9 Douglas NJ, White DP, Weil JV, et al. Hypoxic ventilatory response decreases during sleep in man. Am Rev Respir Dis 1982;125:286-9.

${ }^{10}$ Sodal IE, Bowman RR, Filley GF. A fast response oxygen analyser with high accuracy for respiratory gas measurements. J Appl Physiol 1968;25:181-3.

11 Scholander PF. Analyser for accurate estimation of respiratory gases in one half cubic cm samples. J Biol Chem 1947; 167:235-50.

12 Rechtschaffen A, Kales A, eds. A manual of standardised terminology, techniques and scoring system for sleep stages of human subjects. Bethesda: National Institute of Neurological Disease and Blindness, 1968. (NIH publication No 204.)

${ }^{13}$ Steele RGD, Torrie JH. Principles and procedures of statistics. New York: McGraw-Hill, 1960:110.

${ }^{14}$ Ostergaard T. The excitability of the respiratory centre during sleep and during Evipan anaesthesia. Acta Physiol Scand 1944;8:1-15.
${ }^{15}$ Robin ED, Whaley RD, Crump CH, Travis DM. Alveolar gas tensions, pulmonary ventilation and blood $\mathrm{pH}$ during physiological sleep in normal subjects. J Clin Invest 1958;37:981-9.

${ }^{16}$ Reed DJ, Kellogg RH. Effect of sleep on hypoxic stimulation of breathing at sea level and altitude. J Appl Physiol 1960;15:1130-4.

${ }^{17}$ Bolton DPG, Herman S. Ventilation and sleep state in the new-born. J Physiol (Lond) 1974;240:67-77.

${ }^{18}$ Hathorn MKS. The rate and depth of breathing in new-born infants in different sleep states. $J$ Physiol (Lond) 1974;243:101-13.

${ }^{19}$ Finer NN, Abroms IF, Taeusch HW. Ventilation and sleep state in new-born infants. $J$ Pediatr 1976;89:100-8.

${ }^{20}$ Purcell M. Response in the new-born to raised upper airway resistance. Arch Dis Child 1976;51:602-7.

${ }^{21}$ Fagenholz SA, O'Connell K, Shannon DC. Chemoreceptor function and sleep state in apnoea. Pediatrics 1976;58:31-6.

22 Tabachnik E, Muller NL, Bryan AC, Levison H. Changes in ventilation and chest wall mechanics during sleep in normal adolescents. J Appl Physiol 1981;51:557-64.

${ }^{23}$ Remmers JE, Bartlett D, Putnam MD. Changes in the respiratory cycle associated with sleep. Respir Physiol 1976:28:227-38.

${ }^{24}$ Orem J, Netick A, Dement WC. Breathing during sleep and wakefulness in the cat. Respir Physiol 1977;30:265-89.

25 Phillipson EA, Murphy E, Kozar LF. Regulation of respiration in sleeping dogs. J Appl Physiol 1976;40:688-93.

${ }^{26}$ Birchfield RI, Sieker HO, Heyman A. Alterations in blood gases during natural sleep and narcolepsy. Neurology 1958;8: 107-12.

${ }^{27}$ Harris EA, Hunter ME, Seelye ER, Vedder M, Whitlock RML. Prediction of the physiological dead-space in resting normal subjects. Clin Sci Mol Med 1973;45:375-86.

${ }^{28}$ Milic-Emili J, Grunstein MM. Drive and timing components of ventilation. Chest 1976;70,suppl: 131-3.

29 Tabachnik E, Lopes J, Muller N, Levison H, Bryan AC Airway resistance during sleep in adults. Fed Proc 1981;40:507 (abstract).

${ }^{30}$ Clark FJ, Euler C von. On the regulation of depth and rate of breathing. J Physiol (Lond) 1972;222:267-95.

${ }^{31}$ Euler C von, Trippenbach T. Exitability changes of the inspiratory "off-switch" mechanism tested by electrical stimulation in nucleus parabrachialis in the cat. Acta Physiol Scand 1976;97:175-88.

${ }^{32}$ Skatrud JB, Dempsey JA, Iber C, Berssenbrugge A Correction of $\mathrm{CO}_{2}$ retention during sleep in patients with chronic obstructive pulmonary disease. Am Rev Respir Dis 1981;124:260-8.

${ }^{33}$ Muller NL, Francis PW, Gurwitz D, Levison H, Bryan AC Mechanism of haemoglobin desaturation during rapid-eyemovement sleep in normal subjects and patients with cystic fibrosis. Am Rev Respir Dis 1980;121:463-9.

${ }^{34}$ Mezon BL, West P, Israels J, Kryger M. Sleep breathing abnormalities in kyphoscoliosis. Am Rev Respir Dis 1980;122:617-21. 